\title{
Solid Phase Extraction and Spectrophotometric Determination of Au(III) with 5-(2-Hydroxy-5-nitrophenylazo)thiorhodanine
}

\author{
Qiufen Hu,*** Xiubin Chen,* Xiangjun Yang,* Zhangjie Huang,* Jing Chen,* and \\ Guangyu YANG*† \\ *Department of Chemistry, Yunnan University, Kunming 650091, P. R. China \\ **Department of Chemistry, Yuxi Teacher's College, Kunming 653100, P. R. China
}

\begin{abstract}
A new chromogenic reagent, 5-(2-hydroxy-5-nitrophenylazo)thiorhodanine (HNATR) was synthesized. A highly sensitive, selective and rapid method for the determination $\mu \mathrm{g}^{-1}$ level of $\mathrm{Au}(\mathrm{III})$ based on the rapid reaction of $\mathrm{Au}(\mathrm{III})$ with HNATR and the solid phase extraction of the colored complex with a reversed phase polymer-based $\mathrm{C}_{18}$ cartridge have been developed. The HNATR reacted with $\mathrm{Au}$ (III) to form a red complex of a molar ratio 1:2 (Au(III) to HNATR) in the presence of $0.05-0.5 \mathrm{~mol} \mathrm{l}^{-1}$ of phosphoric acid solution and emulsifier-OP medium. This complex was enriched by the solid phase extraction with a polymer-based $\mathrm{C}_{18}$ cartridge. The enrichment factor of 100 was achieved. The molar absorptivity of the complex is $1.37 \times 10^{5} 1 \mathrm{~mol}^{-1} \mathrm{~cm}^{-1}$ at $520 \mathrm{~nm}$ in the measured solution. The system obeys Beer's law in the range of $0.01-3 \mu \mathrm{g} \mathrm{ml}^{-1}$. The relative standard deviation for eleven replicates sample of $0.5 \mu \mathrm{g} \mathrm{l}^{-1}$ level is $2.18 \%$. The detection limit, based on the three times of standard deviation is $0.02 \mu \mathrm{g} \mathrm{l}^{-1}$ in the original sample. This method was applied to the determination of gold in water and ore with good results.
\end{abstract}

(Received May 17, 2005; Accepted August 1, 2005)

Gold is one of the most important noble metals due to its wide application in industry and economic activity, yet it is not maturally abundant. A simple, sensitive and selective method for determination of trace gold has been required. Several sophisticated techniques, such as inductively coupled plasma mass spectrometry (ICP-MS), inductively coupled plasma atomic emission spectrometry (ICP-AES), electrochemical, spectrofluorometry, and neutron activation analysis have widely been applied to the determination of gold. ${ }^{1-9}$ The spectrophotometric method still has the advantages in respect of simplicity and low operating costs. For this reason, a wide variety of spectrophotometric methods for the determination of gold have been reported, each chromogenic system has its advantages and disadvantages with respect to sensitivity, selectivity and convenience. ${ }^{10-18}$ The rhodanine reagents had widely been applied for the determination of noble metal ions. This type of reagent has a higher sensitivity and high selectivity. ${ }^{19-24}$ In the search for a more sensitive chromogenic reagent, in this work, a new reagent 5-(2-hydroxy-5nitrophenylazo)thiorhodanine (HNATR) was synthesized and the color reaction of HNATR with Au(III) was carefully studied.

However, the routine spectrophotometric methods are often not sensitive enough to determine low concentrations of gold

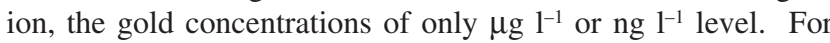
the determination of low concentrations of gold ion, a preconcentration step is usually required. Solid phase extraction is an attractive technique because of its notable advantages (such as higher enrichment factor, reduced contamination of the environment and the ability for rapid and simultaneous preparation of large sample quantities)..$^{25-29}$ In this

$\doteqdot$ To whom correspondence should be addressed.

E-mail: huqiufena@163.com paper, the solid phase extraction of Au-HNATR complex with a reversed phase polymer-based $\mathrm{C}_{18}$ cartridge was studied. The polymer-based $\mathrm{C}_{18}$ is manufactured from a hydrophilic methacrylate polymer, which is functionalized with $\mathrm{C}_{18}$ ligands. It is a reversed-phase solid phase cartridge that provides a broad range of solvent choices and a $\mathrm{pH}$ range from $0-14$. By using the polymer-based $\mathrm{C}_{18}$ cartridge, the Au-HNATR complex was enriched by solid phase extraction in phosphoric acid medium and the enrichment factor of 100 was achieved. Based on this, a highly sensitive, selective and rapid method for the determination of $\mathrm{Au}(\mathrm{III})$ ions in water and ore samples was developed.

\section{Experimental}

\section{Synthesis of HNATR}

In a $100 \mathrm{ml}$ beaker, a 1.54-g portion of 4-nitro-2-aminophenol was dissolved in $45 \mathrm{ml}$ of $95 \%$ ethanol. To this solution, 12.0 $\mathrm{ml}$ of $6.0 \mathrm{~mol} \mathrm{l}^{-1} \mathrm{HCl}$ were added and then the solution was cooled to $0^{\circ} \mathrm{C}$. After this, $7.0 \mathrm{ml}$ of $10 \% \mathrm{NaNO}_{2}$ was added slowly with stiring to obtain a diazotized salt. In another 200 $\mathrm{ml}$ beaker, $1.48 \mathrm{~g}$ of thiorhodanine and $14 \mathrm{ml}$ of $7.5 \mathrm{~mol} \mathrm{l}^{-1}$ ammonia were added. After the solution has been cooled to $0^{\circ} \mathrm{C}$, the above diazotized solution was added dropwise and the mixture was left overnight. The solution was then acidified to $\mathrm{pH} 1$ with concentrated $\mathrm{HCl}$ and the precipitate was isolated by filtration. The crude product was recrystallized with $90 \%$ ethanol 3 times, and the pure H-NATR was obtained with a $62 \%$ yield. Its structure was verified by IR, ${ }^{1} \mathrm{H}-\mathrm{NMR}, \mathrm{MS}$ and elemental analysis. Elemental analysis: $\mathrm{C}_{9} \mathrm{H}_{6} \mathrm{~N}_{4} \mathrm{O}_{3} \mathrm{~S}_{3}$, calculated (found), $34.39(33.98) \% \mathrm{C}, 1.92(2.03) \% \mathrm{H}, 17.82(17.64) \% \mathrm{~N}$, $30.60(30.28) \%$ S. IR $(\mathrm{KBr})\left(\mathrm{cm}^{-1}\right): 3600\left(v_{-\mathrm{OH}}\right), 3280\left(v_{-\mathrm{N}-\mathrm{H}}\right)$; $3080,3050\left(v_{\mathrm{C}=\mathrm{C}-\mathrm{H}}\right) ; 1565,1360\left(v_{-\mathrm{N}=\mathrm{O}}\right) ; 1660\left(\delta_{\mathrm{N}-\mathrm{H}}\right) ; 1548,1515$, 


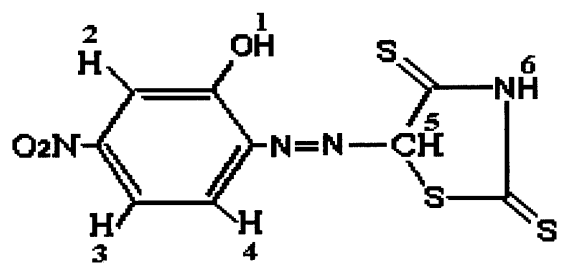

Fig. 1 The structure of HNATR.

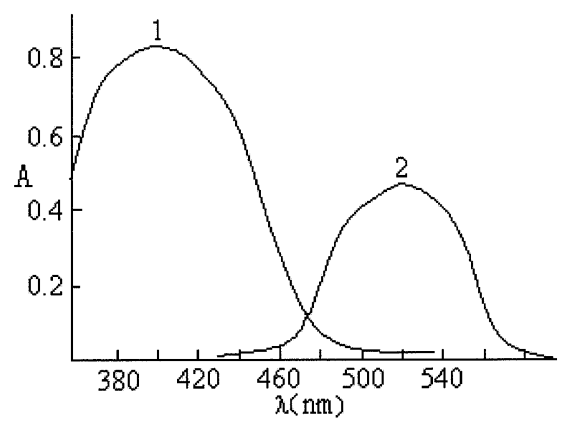

Fig. 2 Absorption spectra of HNATR and its Au(III) complex: 1, HNATR-emulsifier-OP blank against water; 2, HNATR-emulsifier$\mathrm{OP}-\mathrm{Au}(\mathrm{III})$ complex against reagent blank.

$1450\left(v_{\mathrm{C}=\mathrm{C}}\right) ; 1292\left(v_{\mathrm{C}-\mathrm{N}}\right) ; 1171,1215\left(v_{\mathrm{C}=\mathrm{S}}\right) ; 825\left(\delta_{\mathrm{Ar}-\mathrm{H}}\right) ; 806$ $\left(\delta_{\mathrm{C}=\mathrm{C}-\mathrm{H}}\right) . \quad{ }^{1} \mathrm{H}-\mathrm{NMR}$ (solvent: acetone- $\left.d_{6}\right)(\delta, \mathrm{ppm}): 4.85(1 \mathrm{H}, \mathrm{s}$, O-H, H 1); 7.68 (1 H, s, Ar-H, H 2); 7.78 (1 H, d, Ar-H, H 3); 7.25 (1 H, d, Ar-H, H 4); 2.56 (1 H, s, -C-H, s, H 5). MS (EI) $(\mathrm{m} / \mathrm{z}): 314\left(\mathbf{M}^{+}\right)$. All those results show that the HNATR has the structure of Fig. 1.

\section{Apparatus}

A UV-160A spectrophotometer (Shimadzu Corporation, Tokyo, Japan) equipped with $1 \mathrm{~cm}$ microcells $(0.5 \mathrm{ml})$ was used for all absorbance measurements. The $\mathrm{pH}$ values were determined with a Beckman $\phi 200 \mathrm{pH}$ meter (Beckman Instruments, Fullerton, CA, USA). The extraction was performed on a Waters solid phase extraction (SPE) device (that can prepare 20 samples simultaneously), and a reversed phase Polymer $\mathrm{C}_{18}{ }^{\mathrm{TM}}$ cartridge (methacrylate polymer functionalized with $\mathrm{C}_{18}$ ligands, $10 \mathrm{~mm}$ i.d., $15 \mathrm{~mm}, 30 \mu \mathrm{m}$ particle) was obtained from Beijing Genosys Technologies, P. R. China.

\section{Reagents}

All solutions were prepared with ultra-pure water obtained from a Milli-Q50 SP Reagent Water System (Millipore Corporation, USA). High purity dimethyl formamide (DMF) (Fisher Corporation, USA) was used. A $3.0 \times 10^{-4} \mathrm{~mol} \mathrm{l}^{-1}$ of HNATR solution was prepared by dissolving HNATR in DMF. A stock standard solution of gold $\left(1.0 \mathrm{mg} \mathrm{ml}^{-1}\right)$ was obtained from Chinese Material Standard Center, and a working solution of $0.5 \mu \mathrm{g} \mathrm{ml}^{-1}$ was prepared by diluting this solution. A $5 \mathrm{~mol}$ $1^{-1}$ solution of phosphoric acid was used. Emulsifier-OP solution $(2.0 \%, \mathrm{v} / \mathrm{v})$ was prepared by dissolving emulsifier-OP with water. All chemicals used were of analytical grade unless otherwise stated.

\section{General procedure}

To a standard or sample solution containing no more than 3.0 $\mu \mathrm{g}$ of $\mathrm{Au}(\mathrm{III})$ in a $100 \mathrm{ml}$ of calibrated flask, $5 \mathrm{ml}$ of $5 \mathrm{~mol}^{-1}$ of phosphoric acid solution, $5.0 \mathrm{ml}$ of $3.0 \times 10^{-4} \mathrm{~mol} \mathrm{l}^{-1}$ HNATR

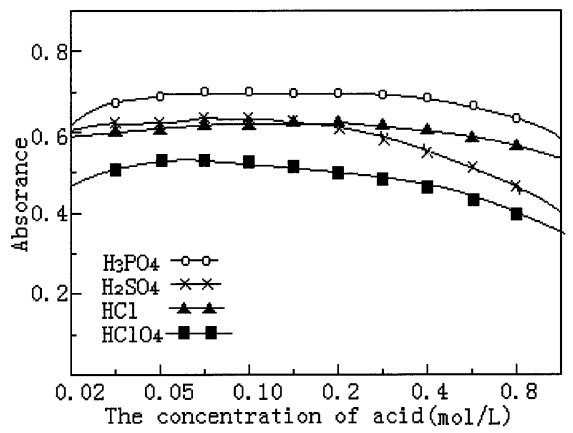

Fig. 3 The effect of acid on the color reaction of HNATR with $\mathrm{Au}(\mathrm{III})$. The concentration of $\mathrm{Au}(\mathrm{III})$ is $1.0 \mu \mathrm{g} \mathrm{ml}^{-1}$, other conditions as in standard procedure.

solution and $3.0 \mathrm{ml}$ of $2.0 \%$ emulsifier-OP solution were added. The mixture was diluted to volume of $100 \mathrm{ml}$ and mixed well. After $10 \mathrm{~min}$, the solution was passed through the polymerbased $\mathrm{C}_{18}$ cartridge at a flow rate of $20 \mathrm{ml} \mathrm{min}^{-1}$. After the enrichment was finished, the retained complex is eluted from the cartridge at a flow rate of $5 \mathrm{ml} \mathrm{min}{ }^{-1}$ with $1.0 \mathrm{ml}$ of DMF in the reverse direction. The eluent was adjusted to the accurate volume of $1.0 \mathrm{ml}$ in a $1.0 \mathrm{ml}$ calibrated flask by adding microamounts of DMF with a $200 \mu \mathrm{l}$ syringe. The absorbance of this solution was measured at $520 \mathrm{~nm}$ in a $1 \mathrm{~cm}$ microcell $(0.5 \mathrm{ml})$ against a reagent blank prepared in a similar way without gold.

\section{Results and Discussion}

\section{Absorption spectra}

The absorption spectra of HNATR and its Au(III) complex are shown in Fig. 2. The absorption peaks of HNATR and its complex in DMF medium are located at $400 \mathrm{~nm}$ and at $520 \mathrm{~nm}$, respectively.

\section{Effect of acidity}

Results showed that the optimal condition for the reaction of $\mathrm{Au}(\mathrm{III})$ with HNATR is in an acid medium. Therefore, the effects of hydrochloric acid, sulfuric acid, perchloric acid, and phosphoric acid, on the color reaction of $\mathrm{Au}$ (III) with HNATR were studied. Experiments show that phosphoric acid has the best effect, and the concentration of phosphoric acid within a $0.05-0.5 \mathrm{~mol} \mathrm{l}^{-1}$ was found to give a maximum and constant absorbance (Fig. 3), so $5 \mathrm{ml}$ of phosphoric acid was recommended.

\section{Effect of surfactants}

The effects of surfactants on the Au(III)-HNATR system were studied. The results (Table 1) show that, in the absence of surfactants, anionic surfactants or cationic surfactants, the $\mathrm{Au}(\mathrm{III})$-HNATR chromogenic system gives a low absorption, whereas in the presence of nonionic surfactants, the absorption of the chromogenic system increases markedly. Various nonionic surfactants enhance the absorbance in the following sequence: emulsifier-OP > Tween-80 > Tween-20 > Tween-60. Accordingly, the emulsifier-OP was the best additive, and the use of $1.5-4 \mathrm{ml}$ of emulsifier-OP solution give a constant and maximum absorbance. Consequently, the use of $3.0 \mathrm{ml}$ was recommended. 
Table 1 The effect of surfactants on Au(III)-HNATR chromogenic system

\begin{tabular}{lcccrrrrr}
\hline Surfactant & Absence & Emulsifier-OP & Tween-80 & Tween-20 & Tween-60 & SDS & CTMAB & CPB \\
\hline$\lambda_{\max }(\mathrm{nm})$ & 500 & 520 & 515 & 510 & 505 & 500 & 505 & 500 \\
$\varepsilon\left(\times 10^{4}\right) 1 \mathrm{~mol}^{-1} \mathrm{~cm}^{-1}$ & 9.24 & 13.7 & 10.2 & 11.5 & 9.65 & 8.21 & 6.35 & 6.68 \\
\hline
\end{tabular}

Table 2 Tolerance limits for the determination of $1.0 \mu \mathrm{g}$ of $\mathrm{Au}(\mathrm{III})$ with HNATR (relative error $\pm 5 \%$ )

\begin{tabular}{|c|c|}
\hline Ion added & Tolerate/mg \\
\hline $\mathrm{NO}_{3}{ }^{-}, \mathrm{K}^{+}, \mathrm{BO}_{4}^{3-}, \mathrm{Na}^{+}$ & 50 \\
\hline $\mathrm{Li}^{+}, \mathrm{Al}^{3+}, \mathrm{PO}_{4}^{3-}, \mathrm{NO}_{2}^{-}, \mathrm{SO}_{4}^{2-}, \mathrm{ClO}_{4}^{-}$ & 20 \\
\hline $\mathrm{Ca}^{2+}, \mathrm{Mg}^{2+}, \mathrm{SO}_{3}{ }^{2-}, \mathrm{Sr}^{2+}, \mathrm{Ba}^{2+}, \mathrm{IO}_{3}^{-}, \mathrm{BrO}_{3}^{-}, \mathrm{ClO}_{3}^{-}$ & 10 \\
\hline $\mathrm{Mn}^{2+}, \mathrm{Ce}^{4+}, \mathrm{WO}_{4}^{2-}, \mathrm{MoO}_{4}{ }^{2-}, \mathrm{UO}_{4}{ }^{2-}, \mathrm{Fe}^{3+}$ & 4 \\
\hline $\mathrm{Ti}(\mathrm{IV}), \mathrm{Bi}^{3+}, \mathrm{VO}_{3}^{-}, \mathrm{CrO}_{4}{ }^{2-}, \mathrm{Zr}^{4+}, \mathrm{F}^{-}, \mathrm{Fe}^{2+}, \mathrm{Cl}^{-}$ & 1 \\
\hline $\mathrm{Cd}^{2+}, \mathrm{Cr}^{3+}, \mathrm{La}^{3+}, \mathrm{SnO}_{3}{ }^{2-}, \mathrm{Zn}^{2+}, \mathrm{Co}^{2+}, \mathrm{Ni}^{2+}$ & 0.5 \\
\hline $\mathrm{Ru}^{3+}, \mathrm{Bi}^{3+}, \mathrm{Pb}^{2+}, \mathrm{Sb}^{3+}, \mathrm{Th}^{4+}, \mathrm{Br}^{-}, \mathrm{OsO}_{5}^{2-}, \mathrm{I}^{-}, \mathrm{Cu}^{2+}$ & 0.2 \\
\hline $\mathrm{SeO}_{3}^{2-}, \mathrm{TeO}_{3}^{2-}, \mathrm{S}_{2} \mathrm{O}_{3}^{2-}, \mathrm{Ag}^{+}$ & 0.1 \\
\hline $\mathrm{Ir}^{4+}, \mathrm{Rh}^{3+}, \mathrm{Ru}^{3+}$ & 0.05 \\
\hline $\mathrm{Pt}^{4+}, \mathrm{Hg}^{2+}$ & 0.01 \\
\hline $\mathrm{CN}^{-}, \mathrm{SCN}^{-}$ & 0.005 \\
\hline
\end{tabular}

\section{Effect of HNATR concentration}

For up to $3.0 \mu \mathrm{g}$ of $\mathrm{Au}(\mathrm{III})$, the use of $5 \mathrm{ml}$ of $3.0 \times 10^{-4} \mathrm{~mol}$ $1^{-1}$ of HNATR solution was found to be sufficient for a complete reaction. Accordingly, $5.0 \mathrm{ml}$ of HNATR solution were added in all further measurements.

\section{Stability of the chromogenic system}

After the components are mixed, the absorbance reaches its maximum within $10 \mathrm{~min}$ at room temperature and remains stable for at least $5 \mathrm{~h}$. After having been extracted into the DMF medium, the complex was stable for at least $8 \mathrm{~h}$.

\section{Solid phase extraction}

Both the enrichment and the elution were carried out on a Waters SPE device. The flow rate was set to $20 \mathrm{ml} \mathrm{min}^{-1}$ for enrichment and $5 \mathrm{ml} \mathrm{min}{ }^{-1}$ for elution.

Some experiments were carried out in order to investigate the retention of HNATR and its $\mathrm{Au}(\mathrm{III})$ complex on the cartridge. It was found that the HNATR and its $\mathrm{Au}(\mathrm{III})$ complex are retained on the cartridge quantitatively when they pass the cartridge as phosphoric acid medium. The capacity of the cartridge was determined as $26 \mathrm{mg}$ for $\mathrm{Au}(\mathrm{III})$-HNATR complex in $100 \mathrm{ml}$ of solution. In this experiment, the maximum amount of gold is only $3.0 \mu \mathrm{g}$. Therefore, the cartridge has adequate capacity to enrich the $\mathrm{Au}(\mathrm{III})$-HNATR complex.

In order to choose a proper eluent for the retained HNATR and its $\mathrm{Au}$ (III) complex. We studied various organic solvents. For eluting the $\mathrm{Au}(\mathrm{III})$-HNATR complex from the cartridge, the volume of the solvent needed is $0.8 \mathrm{ml}$ for DMF, $1.2 \mathrm{ml}$ for isopentyl alcohol, $1.4 \mathrm{ml}$ for acetone, $1.4 \mathrm{ml}$ for acetonitrile, 1.8 $\mathrm{ml}$ for ethanol, and $2.0 \mathrm{ml}$ for methanol. The maximum enrichment was achieved when DMF was selected as eluent. So the DMF was selected as eluant. The experiment shows that it was easier to elute the retained HNATR and its $\mathrm{Au}$ (III) complex in reverse direction than in forward direction, so it is necessary to reverse the cartridge during elution. Since $1.0 \mathrm{ml}$ of DMF was sufficient to elute the HNATR and its Au(III) complex from cartridge at a flow rate of $5 \mathrm{ml} \mathrm{min}^{-1}$, the volume of $1.0 \mathrm{ml}$ was selected.

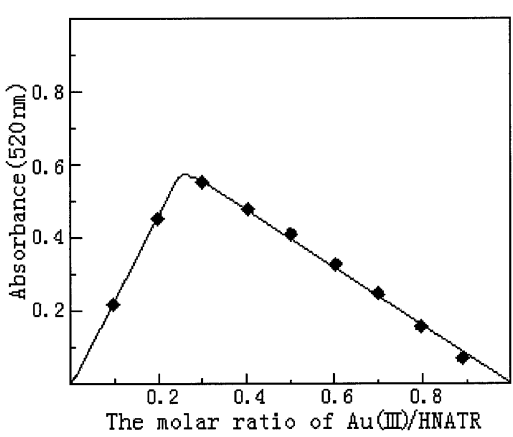

Fig. 4 Composition of $\mathrm{Au}(\mathrm{III})$-HNATR complex by continuous variation method. The concentration of $\mathrm{Au}(\mathrm{III})+\mathrm{HNATR}$ was $1.1 \times$ $10^{5} \mathrm{~mol} \mathrm{l}^{-1}$, other conditions as in standard procedure.

\section{Calibration curve and sensitivity}

The calibration curve showed that the system obeys Beer's law in the concentration range of $0.01-3 \mu \mathrm{g} \mathrm{Au}$ (III) per $\mathrm{ml}$ in the measured solution. The linear regression equation obtained was $A=0.695 C\left(\mu \mathrm{g} \mathrm{ml}^{-1}\right)+0.0163(r=0.9991)$. The molar absorptivity was calculated to be $1.37 \times 10^{5} 1 \mathrm{~mol}^{-1} \mathrm{~cm}^{-1}$ at 520 $\mathrm{nm}$. The relative standard deviation at a concentration level of $0.5 \mu \mathrm{g} \mathrm{l}^{-1}$ of $\mathrm{Au}$ (III) (11 repeated determinations) was $2.18 \%$. The detection limit, based on three times of the standard deviation, is $0.02 \mu \mathrm{g} \mathrm{l}^{-1}$ in the original sample.

\section{Interference}

The influence of foreign ions on the determination of $\mathrm{Au}(\mathrm{III})$ was examined using the general procedure. The tolerance limit was taken as the ratio of foreign ions to the ion being determined that causes a $\pm 5 \%$ error in the absorbance value. The results are listed in Table 2. The result shows that most common ions do not interfere with the determination. This method is highly selective.

\section{Composition of the complex}

The composition of the complex was determined by continuous variation (Fig. 4) method and by molar ratio (Fig. 5) method. Both showed that the molar ratio of $\mathrm{Au}$ (III) to HNATR is $1: 3$. The formation constant was estimated to be $4.21 \times 10^{18}$ as described in the literature. ${ }^{30}$

\section{Application}

For water samples, the samples were acidified with phosphoric acid and filtrated through a $0.45 \mu \mathrm{m}$ filter. The gold contents were analyzed according to a general procedure. The results (deducting the reagent blank) are shown in Table 3. An ICP-MS method was used as a reference method and the results are also shown in Table 3.

A $1.0 \mathrm{~g}$ portion of ore sample is weighed into a $50 \mathrm{ml}$ Teflon high-pressure microwave acid-digestion bomb (Fei Yue Analytical Instrument Factory, Shanghai, China). To this, 10 $\mathrm{ml}$ of aqua regia was added. The bombs were sealed tightly and then positioned in the carousel of the microwave oven (Model WL 5001, 1000 W, Fei Yue Analytical Instrument Factory, 
Table 3 Determination of gold in the water and ore samples

\begin{tabular}{lcccc}
\hline \multicolumn{1}{c}{ Sample } & ICP-MS method & Found & RSD, \% $(n=5)$ \\
\hline River water & $5.87\left(\mu \mathrm{g} \mathrm{l}^{-1}\right)$ & $5.72\left(\mu \mathrm{g} \mathrm{l}^{-1}\right)$ & 3.2 & 8.8 \\
Planting effluents & $28.5 \quad\left(\mu \mathrm{g} \mathrm{l}^{-1}\right)$ & $29.2 \quad\left(\mu \mathrm{g} \mathrm{l}^{-1}\right)$ & 3.5 & 94 \\
Ore GBW(E)070012 & $0.368\left(\mathrm{~g} \mathrm{~T}^{-1}\right)$ & $0.379\left(\mathrm{~g} \mathrm{~T}^{-1}\right)$ & 3.0 \\
Ore GBW(E)070014 & $3.52\left(\mathrm{~g} \mathrm{~T}^{-1}\right)$ & $3.64\left(\mathrm{~g} \mathrm{~T}^{-1}\right)$ & 96 \\
\hline
\end{tabular}

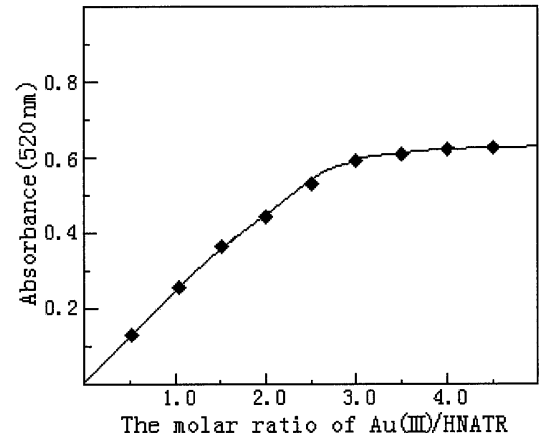

Fig. 5 Composition of $\mathrm{Au}(\mathrm{III})-\mathrm{HNATR}$ complex by molar ratio method. The concentration $\mathrm{Au}(\mathrm{III})$ was $0.35 \times 10^{5} \mathrm{~mol} \mathrm{l}^{-1}$, other conditions as in standard procedure.

Shanghai, China). The system was operated at full power for 30 min. The digested material was evaporated to incipient dryness. Then, $20 \mathrm{ml}$ of $5 \%$ phosphoric acid was added and each mixture was heated close to boiling to leach the residue. After the mixture was cooled, the residue was filtrated and the undissolved residure was washed with $5 \%$ phosphoric acid twice. The leachate was collected into a $100 \mathrm{ml}$ calibrated flask quantitatively and the gold contents were analyzed according to a general procedure. The results (deducting the reagent blank) are also shown in Table 3. An ICP-MS method as was used a reference method and the results are also shown in Table 3.

\section{Conclusion}

This method exhibits high selectivity and high sensitivity. HNATR is a sensitive and selective spectrophotometric reagent for gold. The molar absorptivity of the complex reaches $1.37 \times$ $10^{5} 1 \mathrm{~mol}^{-1} \mathrm{~cm}^{-1}$. Most foreign ions do not interfere with the determination. By solid phase extraction with $\mathrm{C}_{18}$ cartridge, the HNATR-Au(III) complex in $100 \mathrm{ml}$ solution can be concentrated to $1.0 \mathrm{ml}$, so the enrichment fact of 100 was achieved. The detection limit reaches $0.02 \mu \mathrm{g} \mathrm{l}^{-1}$ in the original samples, and $\mu \mathrm{g}^{-1}$ level of gold can be determined with good results.

\section{Acknowledgements}

This work was supported by the National Natural Science Foundation of China (20471051) and the Key Natural Science Foundation of Yunnan Province (2005K021).

\section{References}

1. S. Terashima and M. Taguchi, Bunseki Kagaku, 1999, 48,
847.

2. R. K. Malhotra, G. V. Ramanaiah, and K. Satyanarayana, At. Spectrosc., 1999, 20, 92.

3. N. Zuzana and K. Petr, Fresenius J. Anal. Chem., 2000, 367,369 .

4. B. Lack, T. Nyokong, and J. Duncan, Anal. Chim. Acta, 1999, 385, 393.

5. R. D. Ye and S. B. Khoo, Analyst, 1999, 124, 353.

6. C. M. Wang, Y. Sun, H. L. Li, and H. L. Zhang, Anal. Chim. Acta, 1998, 361, 133.

7. M. Dequaire, C. Degrand, and B. Limoges, Anal. Chem., 2000, 72, 5521.

8. O. Kiwamu, S. Gen, and T. Yoshiyuki, Chem. Geol., 1999, $157,189$.

9. D. H. Gunther and A. Christoph, J. Anal. At. Spectrom., 1999, 14, 1363.

10. P. Anjali, Talanta, 1998, 46, 583.

11. T. Koh, T. Okazaki, and M. Ichikawa, Anal. Sci., 1986, 2, 249.

12. Z. T. Zeng and Q. H. Xu, Talanta, 1992, 39, 409.

13. I. E. Lichtenstein, Anal. Chem., 1975, 47, 465.

14. F. M. EI-Zawawy, M. F. EI-Shahat, A. A. Mohamed, and M. T. Zaki, Analyst, 1995, 120, 549.

15. G. L. Long and J. D. Wineforder, Anal. Chem., 1983, 55, $712 \mathrm{~A}$.

16. G. L. Long and J. D. Wineforder, Anal. Chem., 1980, 52, 2242.

17. J. Medinilla, F. Ales, and F. G. Sanchez, Talanta, 1986, 33, 329.

18. Z. J. Li, J. M. Pan, and J. Tang. Anal. Bioanal. Chem., 2003, 375, 408.

19. Q. F. Hu, G. Y. Yang, and J. Y. Yin, J. Environ. Monit., 2002, 4, 956.

20. E. Tang, G. Y. Yang, and J. Y. Yin, Spectrochim. Acta Part A, 2003, 59, 651 .

21. G. G. Alfonso and J. L. G. Ariza, Microchem. J., 1981, 26, 574.

22. F. M. El-Zawawy, M. F. El-Shahat, A. A. Mohamed, and M. T. M. Zaki, Analyst, 1995, 120, 549.

23. S. D. Shen and J. M. Pan, Chin. J. Phys. Chem. Test. B, 1997, 33, 443.

24. H. C. Yin, Q. F. Hu, Q. Lin, and G. Y. Yang, S. Afr. J. Chem., 2005, 58, 57.

25. Q. F. Hu, G. Y. Yang, and J. Y. Yin, Talanta, 2002, 57, 751.

26. Q. F. Hu, G. Y. Yang, Z. J. Huang, and J. Y. Yin, Talanta, 2002, 58, 467.

27. G. Y. Yang, X. C. Dong, Q. F. Hu, and J. Y. Yin, Anal. Lett., 2002, 35, 1735.

28. Z. Li, G. Y. Yang, B. X. Wang, and J. Y. Yin, J. Chromatogr., A, 2002, 971, 243.

29. Q. F. Hu, X. H. Wu, Z. J. Huang, G. Y. Yang, and J. Y. Yin, S. Afr. J. Chem., 2005, 58, 64.

30. F. J. C. Rossotti and H. Rossotti, "The determination of stability constants and other equilibrium constants in solution", 1st ed., 1961, McGraw-Hill, New York, 64. 